\title{
Special Issue on Advances in understanding and modelling the micromechanisms of fracture and fatigue
}

\author{
Andrey P Jivkov¹, James Marrow², Andrey Shanyavskiy ${ }^{3}$ \\ ${ }^{1}$ Department of Mechanical, Aerospace and Civil Engineering, University of Manchester, Sackville \\ Street, Manchester M13 9PL, UK. \\ ${ }^{2}$ Department of Materials, University of Oxford, Parks Road, Oxford OX1 3PH, UK. \\ ${ }^{3}$ Aviation Register for Russia Federation, Airport Sheremetievo-1, PO Box 54, Moscow region, \\ Chimkinskiy State, 141426, Russia.
}

The articles included in this issue have been prepared by invited authors who presented their work at the last meeting of Technical Committee 2 on Micromechanisms of the European Structural Integrity Society. The meeting was organised as a Symposium within the $9^{\text {th }}$ International Conference on Microstructure \& Micromechanisms of Fracture, held on June 2628, 2019 in Brno, Czechia. The selection represents as well as possible the breath of activities in our Technical Committee, dedicated to uncovering the mechanisms responsible for materials' degradation by a variety of experimental methods and modelling approaches at different length scales and in different classes of materials. The issue includes papers dealing with graphene-based nano-structures (Kotrechko et al.) and atomic scale modelling of metallic (Hansson et al., Stepanova and Bronnikov) and polymeric (Umeno et al.) materials, as well as atomic scale experimental observations of cyclic behaviour (Obrtlik and Šulák). These are complemented by papers studying experimentally the deformation and fracture behaviour at higher lengths scales of emerging materials - high entropy alloys (Ray et al.), superalloys (Lindström et al.), and superaustenitic steels (Polák and Petráš) - and of structural components (Shanyavskiy and Banov). A set of papers deal with numerical modelling of fatigue, including effects of material constitutive modelling (Antunes et al., Azeez et al.), crack closure (Camas et al.) and stress intensity range (Vojtek et al.), and fracture of functionally graded (Petrova and Schmauder) and layered (Žák and Pippan) materials. Finally, three papers are dedicated to cement-based materials, including effects of additions on mortar behaviour (Gruszczyński and Malgorzata), effects of interfacial transition zones on concrete behaviour (Wang et al.), and analysis of fibre-reinforced cement-based composites (Vala and Kozak). We hope that our selection, representing the latest progress in the research of all authors, will be of interest to the wide audience of the journal. 